\title{
Language, NGOs and Inclusion: The Donor Perspective
}

Angela Crack, University of Portsmouth

Listening to communities is valued by UK's Department of International Development (DFID) for contributing to 'beneficiary' empowerment and programme efficiency. This paper is based on interviews with elite DFID officials to explore their understandings on how they expect NGOs to engage with local languages and the role of language intermediaries. It uncovers their perceptions of the ways that languages and cultural knowledge shape NGO relationships with communities. It finds that the officials assume that listening is unproblematic for NGOs, and ask few questions about translation and interpretation. It concludes by reflecting on policy implications and directions for further research.

In a highly-cited article in a previous edition of this journal, Mike Powell told of finding "bilingual, regionally oriented development practitioners in West Africa struggling to interpret and reconcile the very different development discourses coming out of Anglo-Nordic and Francophone intellectual traditions" $(2006,523)$. Despite the passing of over a decade since publication, Powell's portrayal is still likely to resonate with development workers who operate in linguistically and culturally diverse environments. A widespread problem in the development NGO sector is poor translation/interpretation capacity in local languages (Footitt et al, forthcoming; Footitt 2017; Luchner 2018). Language needs are often not planned in advance or budgeted for in development projects (Footitt et al 2018). This affects the ability of organisations to listen to communities that they purport to serve. The conventional wisdom in international development is that listening is central to the key stages of a project, from needs-assessment to monitoring and evaluation (M\&E) (Anderson et al 2012). Major donors increasingly expect NGOs to demonstrate that their programmes incorporate meaningful, reciprocal engagement with communities. For example, a persistent theme in UK development policy has been the importance of 'beneficiary' empowerment, participation and feedback (Ireton 2013). This implies the centrality of listening and language in the relationship between aid provider and aid recipient.

It is not clear how donor officials perceive the extent to which listening, translation and interpretation takes place between organisations that they fund and communities that receive aid. This article is an exploratory attempt to understand elite perspectives on the role of listening and language in development practice. It investigates how elite officials at DFID perceive that NGOs listen to local communities and how they expect NGOs to engage with local languages. It uncovers their views on the issues that impede communication and listening. The aim is to provide a baseline of how those in a strategically important position to 
influence policy understand the ways in which languages and cultural knowledge shape relationships with communities. The findings are based on document analysis and semistructured interviews conducted with nine elite informants in 2017.

The article adds to a growing body of scholarship that reflects upon the low priority accorded to local languages in development. There have been longstanding concerns about how the international dominance of English upholds the cultural constructs of colonialism in developing countries (Pennycook 2002; Phillipson 1996), including via the promotion of English in education programmes funded by foreign aid (Seargeant and Erling 2010; Seargeant et al 2017). Criticisms have been made of the lack of language planning in development aid discourse (Taylor-Leech and Benson 2017). There have been calls to include language at the centre of the Millennium/Sustainable Development Goals (Bamgbose 2014; Marinotti 2016; Romaine 2013) and to mobilise indigenous languages to promote national development in low-income countries (Kanana 2013). However, little attention has been paid to the perceptions of donor officials on the role of language in development work. An insight into these perceptions will be useful for academics and decision-makers who are exploring the institutionalised, unfounded assumptions of development policy, particularly relating to 'beneficiary' participation and feedback. This article will also be of interest to practitioners who want to increase the profile and funding for interpretation and translation, and are keen to garner insight into the awareness and receptivity of donors to these issues. Donors may find that it provokes useful questions about whether there are linguistic and cultural 'blind spots' in the ways in which they evaluate the quality of development interventions.

The first section of the article discusses the policy priorities of DFID and the debate surrounding the notion of 'beneficiary voice'. The second section outlines the method of collecting the interview data. The third section presents the research findings. The article concludes by offering thoughts on avenues for further research.

\section{Policy Priorities of the UK's Department of International Development (DFID)}

DFID is the government department that is primarily responsible for administering UK aid, and was established in 1997. The UK has a long-standing commitment to the UN target of spending $0.7 \%$ of gross national income on aid each year (which was enshrined in law by the International Development Act 2015). In 2017, this commitment equated to $£ 13.4$ billion, and DFID is responsible for $74 \%$ of this budget. DFID describes its mission as: "...tackling 
the global challenges of our time including poverty and disease, mass migration, insecurity and conflict. Our work is building a safer, healthier, more prosperous world for people in developing countries and in the UK too" (DFID 2017a). The department's priorities are listed as strengthening global peace, security and governance; strengthening resilience and response to crisis; promoting global prosperity; tackling extreme poverty and helping the world's most vulnerable; and delivering value for money (DFID 2018). It works in countries across the linguistically and culturally diverse regions of Africa, Asia and the Middle East, many of which are labelled as fragile or at risk from fragile neighbouring states. Civil society organisations, including NGOs, are significant beneficiaries of DFID funds. The department claims that working with civil society organisations "forms an integral part of DFID's approach to reducing poverty and plays a vital role in creating open, accountable and inclusive societies" (DFID 2017b, 10).

DFID is consistently under pressure, particularly from the right-leaning news media, to root out corruption and waste and demonstrate cost-effectiveness (Martin 2016). 'Aid fatigue' in domestic public opinion is associated with perceptions of corruption in recipient countries, and so has implications for DFID (Bauhr et al 2010; Henson and Lindstrom 2013). Recent years have seen increasing attempts to enhance the transparency and the efficacy of aid spending by various governments, including the introduction of the International Development (Reporting and Transparency) Act 2006, and submitting the department to the scrutiny of the Independent Commission for Aid Impact. Nonetheless, DFID has performed poorly relative to several other donors for transparency, and the pressure to justify investment in foreign aid is relentless, even leading to some calls for the department to be scrapped altogether (Ghosh and Kharas 2011; Sheldrick 2017).

In turn, DFID have become keen advocates of the evidence agenda, demanding that NGOs demonstrate 'development impact' and 'evaluation rigour'. More money is being disbursed through the 'payment by results' strategy, whereby payments are only made on the achievement of pre-agreed targets. This approach is trumpeted by DFID as being a means to "bring more people out of poverty for good and ensure that we are getting the greatest value for money on behalf of the British taxpayer" (DFID 2014a). Practitioners and academics have criticised the evidence agenda for marginalising the voice of the 'beneficiary' in assessing impact, and have pushed for greater use of participatory evaluation processes (Ahmad 2011; Eyben et al 2015; Valters and Whitty 2017). DFID make the counter-argument that 'payment by results' can support mechanisms that generate feedback from 'beneficiaries', especially where the levels of payment are dependent on how 'beneficiaries' rate aid providers (DFID 2014a). 
'Voice' in international development is thus equally lauded by DFID and its critics, although framed in different ways. The first commitment of DFID's core 'Leaving No One Behind' policy is to work to eradicate poverty by 'listening and responding to the voices of those left furthest behind, such as people with disabilities, children, older people and those who face discrimination based on who they are or where they live.' (DFID 2017c). DFID's commitment to 'listening' and 'voice' is framed by their interest in assessing the 'added value' of an inclusive approach for achieving internationally determined development goals (Carter 2015). In contrast, critics of mainstream development argue that 'voice' must be delinked from the donor's desire for measurement and control. Rather, it should be valued as a way of 'handing over the stick' to poor people and be used to prompt critical self-reflection on behalf of development professionals (Chambers 1997).

What is often implicit in the policy debate about 'voice' is the assumption that those speaking (aid recipients) and those listening (aid providers) can communicate in the same language. DFID's reach extends across territories with hundreds of languages and dialects. NGOs, feeling the pressure of the evidence agenda, face a significant challenge in ensuring that they have sufficient language capacity to communicate with 'beneficiaries' (Footitt et al 2018; Luchner 2018). The next section outlines the research methods that were chosen to explore the perceptions of elite officials on how NGOs listen to local communities and how they expect NGOs to engage with local languages.

\section{Methodology}

These findings were collected as part of a larger AHRC-funded research project for which I am co-investigator. The project, titled The Listening Zones of NGOs, investigates the role of languages in the relationships that NGOs build with local communities. The project drew upon dozens of interviews with NGO staff members as well as donor officials, and a full account of the research will be detailed in a forthcoming book (Footitt et al forthcoming). This article, however, purely focuses on the data relating to DFID and is designed to be read as a 'stand-alone' study. Nonetheless, the genesis of this article is relevant to understanding the context of the interviews and the information given to interviewees.

The study was approved by the Ethics Committee at the University of Portsmouth before interviewees were contacted. The Committee approved the information that was given to interviewees about how their data would be used and how their confidentiality would be protected. This information explained that the purpose of the study and stated that the outputs of the research would include academic publications as well as policy 
recommendations for NGOs and donors (please refer to Footitt et al 2018 for the latter). Nine senior DFID officials agreed to be interviewed on condition of anonymity. They included individuals with significant leadership, management and advisory responsibilities. Their job titles cannot be divulged because otherwise they would be easily identifiable. They were targeted because it was thought more likely that their views would have an impact on DFID decision-making and policy implementation, due to their strategic position in the organisation. Their contact details were gathered via information online and 'snowballing'. The sample was gender-balanced, including four men and five women. The interviews were semi-structured, lasted from 40m-1 hour, and carried out either face-to-face or by telephone. The interviewees spoke in a private capacity, and not as representatives of DFID.

Questions posed to the interviewees included: How is the concept of listening used within DFID? Do you and/or your DFID colleagues discuss and reflect upon the quality of listening that takes place between NGOs and local communities? Does DFID reflect upon the role that languages and cultural knowledge play in the listening? Does DFID expect NGOs to take foreign language needs into account when planning a programme, either by the headquarters or by country staff? How would DFID expect language mediators to be recruited/sought in the local context of programme work?

Data was manually sorted into emergent codes, which enabled the capture of recurrent ideas and meanings (Creswell 2008). Document analysis was undertaken as a validation strategy, drawing on information available on DFID's webpages. The dataset included corporate reports, official guidance, policy papers, transparency data, consultation reports, impact assessments and research and analysis, from 1997 (the year of DFID's creation) to 2016.

The findings are of limited generalisability because of the small sample and may not represent wider sentiment within DFID. Another caveat to add is that the interviewees' responses may have been coloured by the questions on politically sensitive topics (i.e. regarding the performance of DFID-funded organisations, in the context of domestic controversy about the effectiveness of aid). It is interesting that some interviewees nonetheless provided some critical responses that diverged from the 'official line', suggesting that the assurances of confidentiality helped them to feel comfortable in disclosing their opinions. 


\section{Findings}

\section{Listening to communities}

Interviewees were firstly asked how the concept of listening is used in DFID, to get a sense of the institutional context. Five reported that it was used in terms of 'beneficiary' feedback, particularly noting that listening to communities was important for M\&E. 'Beneficiary' feedback was described as "fundamentally... part of good development" (Int.9). Listening was also acknowledged by four respondents as important in programme/project design, including needs-assessment. However, interviewees remarked that DFID does not 'listen' to 'beneficiaries' directly. Instead, DFID accesses the 'beneficiaries' voice' through reports provided by the project implementers. There are some exceptions: “...the most direct opportunity for [DFID] to have the most direct conversation with someone from a country that you're working in would be in the context of a field visit." (Int.7) DFID expects NGOs to listen to communities, or at least listen to 'beneficiaries' through the locally-based organisations that they are partnering with. NGOs are understood to be responsible for relaying this feedback to DFID and keeping them abreast of opinion on the ground. This supposed connection with communities is seen as the main added value of NGOs as project implementers; listening was said to be "part of the selling point of NGOs, right?" (Int.6)

Three interviewees with DFID careers stretching back for decades distinguished between different periods of the institution's development in terms of listening activity. When DFID implemented projects in its early years, it was said that there was more opportunity to listen to local communities directly via participatory rural appraisal and other methodologies. DFID's subsequent shift in focus to budgetary support resulted in listening "more to people in the centre: technocrats and politicians" (Int.6). Now that DFID had recently moved to project support, it was felt that opportunities to listen to communities had increased through M\&E processes, albeit NGOs are now intermediaries in this 'listening relationship'. Respondents pointed to DFID's guidelines for stakeholder consultations as an example of best practice for NGOs in listening to communities for the purpose of evidence-based planning and project evaluation. In sum, DFID sees listening as an important part of data collection, to ensure that decisions about aid are informed by "accurate" understandings of the opinions at the grassroots (Int.3).

Having established the consensus about the importance of listening, interviewees were asked about the extent to which they reflected on the quality of listening that takes place between NGOs and communities, particularly in terms of whether NGOs have appropriate language skills. The most consistent message of the interviews was that DFID assumes that NGOs listen to communities, and that they are good at doing so: "The whole concept of 
beneficiary feedback would be based on the ability to actually understand the feedback from the beneficiaries so a coherent level of appropriate and different language knowledge would be something that would be assumed." (Int.3) Respondents commonly agreed that specific questions are typically not asked of NGOs about whether they have the language competence to listen to communities: "We sort of assume that the NGOs have taken care of it." (Int.1) "It's an assumption rather than something that we check." (Int.2) "We generally feel that NGOs are good on this." (Int.4) "NGOs tend to be good at this stuff." (Int.6) One respondent who was involved in assessing NGO applications for a major funding call explained that DFID's focus at the selection process centred on the credibility of deliverables. However, the credibility of the claims made by the NGOs about listening did not receive the same level of critical analysis: "it was more about "what are you achieving and how will you achieve this?' rather than the methods they used to get their information... I guess the assumption is that people are listening and talking to the communities - if it's going to work that's what they have to do..." (Int.9) Listening therefore has a 'taken-forgranted' status and is generally not problematised - much less the question of how the ability to listen is shaped by the organisation's language capacity. Four respondents remarked that reflection on the quality of listening by NGOs within DFID is not systematic: "it's pretty amateurish and ad hoc". (Int.2)

The ambivalence of the participants was mirrored by the findings of the document analysis. In recent years, DFID has sought to 'embed evaluation' more firmly into all their programmes, including at the design stage, gathering baseline data and evaluating results during and beyond the programme cycle. Policy documents and guidelines have heavily promoted the principle of stakeholder involvement, since listening to 'beneficiaries' is seen as crucial for a successful evaluation strategy. Some evaluation reports have acknowledged that stakeholder involvement has been poor; but there is little in-depth reflection on the reasons for this, or detailed comment on language issues (DFID 2013a, 2014b, 2015a). DFID guidance for implementing organisations emphasises that they should demonstrate that they have designed programmes that incorporate engagement with the local population. However, such guidance typically does not explicitly mention the need to consider language appropriate to the local context (DFID 2013b, 2015b). It also tends to neglect the role of cultural knowledge and issues concerning the use of language intermediaries, which leads to the next topic.

\section{Language and cultural knowledge}


Interviewees were asked about DFID's expectations in regard to NGOs' recruitment of language intermediaries by NGOs. These 'brokers' are an integral part of development interventions, however their role is often overlooked by scholars and policy-makers (Lewis and Mosse 2006; Olivier de Sardan 2005). Language ability is sometimes stipulated in the terms of reference if a team is doing direct field work, and NGOs may be asked about their language competence if they are working in a region of high ethnic tension. However, for the majority of the respondents, it seemed to be the case that the question of human resources needed for language support had not been given deep thought. It was apparent that issues involving language intermediaries are not regularly discussed as part of the working experience of most of the participants. Those at the highest echelons reiterated their presumptions about the language capacity of NGOs: "my assumption is that...the UN and the international NGO community have the right staffing in terms of language." (Int.7) For one respondent who was heavily engaged in research, the lack of interrogation into the recruitment and identity of language intermediaries was highly problematic:

"The focus is on what is being said but there isn't enough focus on how the data has been collected, because very often the people on the ground are market research agencies. They are from the community, they seemingly understand, speak the local language, but they don't have the right kind of training. So the same bunch of people who are out there collecting market information and are trained to ask questions about what brand of soap I use are the same guys who are going to come back and ask if I've been beaten by my husband...By the time [the data is] polished and written up into beautifully formatted English reports, they are very different versions than what has actually been said on the ground." (Int.8)

This is a vivid example of the importance of cultural awareness in research at the local level, especially involving sensitive or taboo subjects with vulnerable people (Bujra 2006). Respondents were asked if DFID reflected on the role that cultural knowledge plays in listening. Here, there was a more positive response, especially in terms of gender, which aligns with DFID's long-standing focus on the rights of women and girls. All the respondents affirmed the importance of cultural awareness by referring to their own personal experience of development work. There was consensus that communicating with people 'on the ground' required more than just competence in the language. "So certainly a lot of the Westerners, even if you speak the language, are not going to be able to express or hear what people want to say because it's much more nuanced than just being able to speak the language... The whole power relation thing of it and the cultural understanding..." (Int.4) It includes an awareness of the importance of the space within which listening takes place. Examples that were given included women in highly patriarchal societies who may not be 
permitted to speak freely in public spaces, and/or who will be inhibited from saying certain things in front of men and other powerful figures such as their mother-in-law. Understanding the complexities of the local context (which interviewees variously suggested includes considerations of ethnicity, caste, clan, disability, and socioeconomic factors) was emphasised as integral in development work.

The interview findings mirrored the document analysis, where references to 'voice', 'inclusion', 'listening' and 'culture' were especially prevalent in DFID's policy and guidance materials on gender-based issues. Guidance on gender mainstreaming advises that consultations should be as inclusive as possible, and that measures on inclusion should be incorporated into M\&E frameworks. Nevertheless, this guidance primarily focuses on awareness of gendered spaces. The role of languages/language intermediaries in a gendersensitive communication strategy is unexplored (DFID 2013c).

One interviewee expressed concern that NGOs funded by DFID may not listen meaningfully to communities. Rather, their funding success rests on their ability to write professional proposals that present a convincing portrayal of their listening relationships with communities. DFID's grant conditions presume that applicants are fluent enough in English to abide by corporate requirements, typically meaning that large (Northern-based) NGOs are the only organisations with the skills and capacity to win funds. Non-English speaking, local organisations with close connections to the grassroots are therefore disadvantaged by funding opportunities that are linguistically exclusionary:

"I don't think this is on purpose but just subconsciously - some who speaks your language, you're automatically drawn towards and this could disadvantage others who don't speak your language who might even be in far more need for support and partnership...So what happens is that normally NGOs come to these local communities and always speak on their behalf and submit proposals on their behalf and get the majority of funding to that community through them... an NGO like Oxfam or Save the Children or whomever, that becomes a proxy representative of that community whether that community likes it or not." (Int.5)

The professionalisation and elitism of NGOs has been termed 'NGOisation' by critical scholars (Choudry and Kapoor 2013). The interviewee emphasised that these views were personal and did not claim that they represented wider sentiment within DFID. It is an interesting indication of divergent views at senior levels that could be interrogated in future research. 


\section{Challenges to listening and communication in development work}

Respondents were invited to reflect upon issues that impede listening relationships in development work. One bemoaned the 'devaluing' of local knowledge across the international development sector as a whole in favour of management skills - a trend that has also been criticised by Mosse (2011). Language competency, cultural awareness and an appreciation for historical context was said to have been downgraded in favour of generic technical expertise. Respondents did, however, sympathise with the challenges facing NGOs who may want to enhance their language capacity. As Tesseur (2017) shows, the resource challenges can be substantial even for an organisation as large as Amnesty International. One interviewee asserted the need for language training for NGO staff, but recognised that this would be difficult in intense situations where there was high staff turnover due to 'burn-out', because acquiring proficiency would require a significant time investment. Squeezed administrative budgets also mean that it would not be "realistic" to expect international staff to be trained in the local languages: "I don't think we would fund NGOs for [language acquisition] either." (Int.2) Three interviewees remarked that the resultsbased framework also restricts the ability of NGOs to devote sufficient attention to issues that cannot be captured by measurable indicators or be shown to contribute to outcomes in concrete ways. The challenge for NGOs that want to improve their language capacity was said to be to: "...[think] about things that are good enough and that are achievable within a restricted cost base..." (Int.2)

Similarly, three respondents recognised that the ability of NGOs to engage fully with communication issues is circumscribed by the pressures of small project cycles: "And there is such a rush - especially for donor-driven projects - there is such a rush to report back within timeframes, sometimes rather difficult timeframes I admit...and most crucial bit of the translation actually gets completely lost in the urgency to transcribe it into English." (Int.8) As Wallace et al have also observed (2007), this time pressure also means that it can be hard for NGOs to build up a relationship of trust with the community. The respondents commonly agreed that trust is essential for a good listening relationship. They noted that NGOs should ideally spend time immersing themselves in the community in advance of submitting a bid, in order to arrive at a more authentic understanding of the community's preferences. However, they recognised that such upfront contextual analysis requires time and flexibility, which is difficult to achieve when chasing after funds and observing the strictures of logframes. This observation parallels Krause's analysis of the negative effects that logframe and fundingrelated pressures have on community relationships for humanitarian NGOs (2014). 
Respondents offered more thoughts on how donors create circumstances inhospitable to listening, interpretation and translation. One criticised the tendency of donors to shy away from sensitive political areas that could incur reputational risk. This means that opportunities to engage with local communities are restricted: "What that means is that sometimes [NGOs] don't take the necessary risk to go into areas that, granted, are risky, and to deal with the problems of that beneficiary community. So language and communication might be excellent but sometimes you're prohibited...by policy directives which limit your engagement in one area or another." (Int.5) Another interviewee argued that DFID's risk-adverse approach underpins the evidence agenda and the focus on cost-effectiveness. The concentration on measurable outcomes and impact distracts attention from the importance of listening: "I think that the problem is that listening - building knowledge and understanding over communities - is hard to quantify. It's difficult to demonstrate that listening contributes to value for money." (Int.1) Another expressed similar thoughts, not specifically in relation to DFID, but regarding international development donors more generally: "And I think a challenge for us as a sector is the way we fund organisations. The fact that we often need, you know, to behave with a certain level of professionalism that maybe we can't expect from the local organisations and also the cycle of funding, the fact that it's shorter and it doesn't lend itself to being able to support these more grassrootsy [sic] organisations... in that way you would want to if you were really trying to understand the local context." (Int.9) As Banks et al (2015) observe, professionalised NGOs have the advantage of being able to express their objectives and impact in the same terminology used by donors. Organisations will be more likely to be funded if they have competence in an elite form of English that incorporates donor jargon.

\section{Conclusion}

In alignment with the Sustainable Development Goals, a core commitment of DFID is "listening and responding to the voices of those left furthest behind" (DFID 2017c). DFID also claims that it values 'beneficiary' participation and aims to empower people and communities. The achievement of these ambitions is minimally dependent upon DFIDfunded NGOs and 'beneficiaries' understanding one another, which is very difficult if they are not able to converse in the same language. 'Beneficiaries' may effectively be rendered voiceless if they cannot be understood in their mother tongue. Language is perhaps the most basic requisite for a listening relationship between aid providers and aid recipients (Marinotti 2016). Customs, traditions and norms shape the ways in which people understand and respond to ideas, and engage in social interactions. Cultural knowledge is therefore also key 
to respectful listening and dialogue. There is increasing criticism of the low priority given to languages and cultural knowledge in development policy (Bamgbose 2014; Marinotti 2016; Taylor-Leech and Benson 2017). Simply put, "Development cannot reach the most marginalized without speaking to them in their own language." (Romaine 2013, 17) However, despite the long-standing interest of practitioners and scholars in the place of listening and language in development (Anderson et al 2012; Cornwall 2007; Cornwall \& Eade 2010), there is a dearth of literature on the perceptions of elite staff in donor agencies on these issues. This article is an exploratory contribution to understanding donor perspectives on the role of listening and language in development work. Nine individuals were interviewed, who occupy strategically important positions at DFID. Document analysis was used as a validation technique, involving scrutiny of a wide range of material over DFID's lifetime, including corporate reports, official guidance, policy papers and impact assessments.

A major finding of the interviews was that DFID generally assumes that NGOs do actually listen to communities, and that they are good at doing so. It also tends to be taken for granted that NGOs have the language capacity to conduct their work. Organisations in receipt of DFID funds are generally not asked questions about interpretation and translation, or if/what language intermediaries are used. The words 'assume/assumption' were the most frequently used, occurring in every interview in regard to NGOs and listening and language competence (sometimes multiple times). This complacency was also evident in the document analysis, where the documents were generally marked by an absence of extended commentary, guidance or reflection about language.

Respondents were more emphatic in discussing the importance of cultural awareness in development work, particularly in terms of reaching out to marginalised groups such as women. This correlates with the relatively more detailed attention given to cultural norms in DFID literature, especially regarding gender. Interviewees expressed sympathy for NGOs that grapple with the unrelenting pressures caused by funding shortages and the tight deadlines for project delivery. They recognised that this can make it difficult for NGOs to invest in language, and to carve out the space needed to build relationships of trust with communities. It was also noted that differences in English competency can magnify the already existing power inequalities between Northern-based NGOs and local organisations. The former are more able to produce documentation to a professional standard that is expected by the donor, and so more likely to receive funding, regardless of their local language capacity. None of the interviewees, bar two, distinguished between different types of Northern-based NGOs or programme/project work in their answers. One respondent mused on the policy implications raised by the interview: "We should ask some questions, really, because some NGOs do it better than others." (Int.1) The findings of this article are 
relevant for donors who want to reflect whether they have given due consideration to the possible relevance of language issues to the achievement of their strategic goals.

The sample size is small and it is not possible to make generalisations about perceptions in DFID more broadly. It is nonetheless indicative of a need for more knowledge generation on the expectations of donors about how NGOs navigate different linguistic and cultural landscapes. This would require a larger group of interviewees, drawn from different levels of the department, and across country offices. It would be useful to explore how elite perceptions about language shape policy-making, especially regarding funding conditions, evaluation frameworks and feedback requirements. For example, do policy discussions involve explicit or implicit references to the language capacity of the implementing organisation; if so, in what ways is this understood to be relevant to achievement of programme/project objectives? Likewise, it would be interesting to investigate how decisionmaking is shaped by elite attitudes about the role of language in development work. For example, do considerations about language capacity influence decisions about which organisations and project proposals are awarded funding; if so, how and why? It would also be insightful to undertake comparative studies between different donors of different language backgrounds. For example, comparisons between Anglophone and non-Anglophone countries; between traditional and emerging donor countries; and between Anglophone donors and multilateral donors that incorporate actors of a variety of languages, such as the European Union.

\section{Bibliography}

Anderson, M. B., D. Brown and I. Jean. 2012. Time to listen: Hearing people on the receiving end of international aid. Cambridge, MA: CDA Collaborative Learning Projects.

Ahmad, T. 2011. The 'Right' Results: Making sure the results agenda remains committed to poverty reduction. Oxford: Oxfam.

Bamgbose, A. 2014. "The language factor in development goals." Journal of Multilingual and Multicultural Development. 35(7): 646-657.

Banks, N., D. Hulme and M. Edwards. 2015. "NGOs, states, and donors revisited: Still too close for comfort?" World Development, 66: 707-718.

Bauhr, M., N. Charron and N. Nasiritousi. 2013. "Does corruption cause aid fatigue? Public opinion and the aid-corruption paradox." International Studies Quarterly. 57(3): 568579. 
Bujra, J. 2006. "Lost in translation? The use of interpreters in fieldwork." In Doing development research. Ed. Vandana Desai and Robert B. Potter, 172-179. London: Sage.

Carter, B. 2015. Benefits to society of an inclusive societies approach. GSDRC Helpdesk Research Report 1232. Governance and Social Development Resource Centre. Birmingham: University of Birmingham. https://www.gov.uk/dfid-researchoutputs/benefits-to-society-of-an-inclusive-societies-approach-gsdrc-helpdeskresearch-report-1232

Chambers, R. 1997. Whose Reality Counts? Putting the first last. London: ITDG Publishing.

Choudry, A. and D. Kapoor, eds. 2013. NGOization: Complicity, contradictions and prospects. London: Zed Books.

Cornwall, A., and D. Eade, eds. 2010. Deconstructing development discourse: Buzzwords and fuzzwords. Oxford: Practical Action Publishing.

Cornwall, A. 2007. "Buzzwords and fuzzwords: deconstructing development discourse." Development in Practice 17(4-5): 471-484.

Creswell, J. W. 2008. Research Design: Qualitative, Quantitative and Mixed Methods Approaches. London: Sage.

DFID. 2013a. "International Development Evaluation Policy." https://www.gov.uk/government/uploads/system/uploads/attachment data/file/20411 9/DFID-Evaluation-Policy-2013.pdf

DFID. 2013b. "Additional Guidance for GPAF Initiatives Focused on Empowerment and Accountability."

https://assets.publishing.service.gov.uk/government/uploads/system/uploads/attachm ent data/file/261855/Additional-Guidance-GPAF-Initiatives-Empowerment-

Accountability-nov13.pdf

DFID. 2013c. "Gender and the Global Poverty Action Fund."

https://assets.publishing.service.gov.uk/government/uploads/system/uploads/attachm ent data/file/207456/GPAF-Gender-Guidelines-june13.pdf

DFID. 2014a. "Payment by Results Strategy: Sharpening incentives to perform."

https://www.gov.uk/government/publications/dfids-strategy-for-payment-by-resultssharpening-incentives-to-perform/payment-by-results-strategy-sharpening-incentivesto-perform

DFID. 2014b, February. "Rapid Review of Embedding Evaluation for UK Department for International Development." https://www.gov.uk/government/uploads/system/uploads/attachment data/file/29220 8/Embedding-Evaluation-Review.pdf 
DFID. 2015a. "DFID's Evaluation Framework for Payment by Results."

https://www.gov.uk/government/uploads/system/uploads/attachment data/file/43605

1/Evaluation-Framework-Payment-by-Results3.pdf

DFID. 2015b. "Smart Rules: Better Programme Delivery"

https://www.gov.uk/government/uploads/system/uploads/attachment data/file/47277 1/Smart Rules 1November to 31 March 2016.pdf

DFID. 2017a. "About us." https://www.gov.uk/government/organisations/department-forinternational-development/about

DFID. 2017b. "Annual Report and Accounts 2016-17."

https://assets.publishing.service.gov.uk/government/uploads/system/uploads/attachm ent data/file/625548/DFID-Annual-Report-and-Accounts-2016-17.pdf

DFID. 2017c. "Leaving no one behind: Our promise."

https://www.gov.uk/government/publications/leaving-no-one-behind-our-

promise/leaving-no-one-behind-our-promise

DFID. 2018. "Development Tracker.” https://devtracker.dfid.gov.uk/ Accessed 12 May 2018.

Eyben, R., I. Guijt, C. Roche and C. Shutt, eds. 2015. The politics of evidence and results in international development: playing the game to change the rules? Oxford: Practical Action Publishing.

Footitt, H. 2017. "International aid and development: hearing multilingualism, learning from intercultural encounters in the history of OxfamGB." Language and Intercultural Communication, 17(4): 518-533.

Footitt, H. A., A. M. Crack and W. Tesseur. 2018. Respecting communities in international development: languages and cultural understanding. https://www.reading.ac.uk/web/files/modern-languages-and-europeanstudies/Listening zones report -EN.pdf

Footitt, H. A., A. M. Crack and W. Tesseur. Forthcoming. Listening, Power and Inclusion: Languages in Development NGOs. Basingstoke: Palgrave.

Ghosh, A. and H. Kharas. 2011. "The money trail: Ranking donor transparency in foreign aid." World Development. 39(11): 1918-1929.

Henson, S. and J. Lindstrom. 2013. "A mile wide and an inch deep? Understanding public support for aid: The case of the United Kingdom." World Development, 42: 67-75.

Ireton, B. 2013. Britain's International Development Policies: A History of DFID and Overseas Aid. Basingstoke: Palgrave.

Kanana, F. E. 2013. "Examining African languages as tools for national development: The case of Kiswahili." The Journal of Pan African Studies, 6(6): 41-48.

Krause, M. 2014. The good project: humanitarian relief NGOs and the fragmentation of reason. Chicago, IL: University of Chicago Press. 
Lewis, D. and D. Mosse, eds. 2006. Development brokers and translators: The ethnography of aid and agencies. Bloomfield, CT: Kumarian Press.

Luchner, C. D. 2018. "Contact zones of the aid chain: The multilingual practices of two Swiss development NGOs." Translation Spaces. 7(1): 44-64.

Marinotti, J. P. 2016. "Symposium on Language and the Sustainable Development Goals:

Final Report." https://sites.google.com/site/languageandtheun/events/2016symposium-conclusions

Martin, D. 2016. "Yes, they really are as bad as the PM admitted: Afghanistan and Nigeria rank among the world's most corrupt countries... yet we give them millions of pounds in aid." Daily Mail, May 11. http://www.dailymail.co.uk/news/article-3583923/Yes-reallybad-PM-admitted-Afghanistan-Nigeria-rank-world-s-corrupt-countries-millionspounds-aid.html\#ixzz4yyJmD4P1

Mosse, D, ed. 2011. Adventures in Aidland: The anthropology of professionals in international development. Oxford: Berghahn Books.

Olivier de Sardan, J. P. 2005. Anthropology and Development: Understanding Contemporary Social Change. London: Zed Books.

Pennycook, A. 2002. English and the discourses of colonialism. London: Routledge.

Phillipson, R. 1996. "Linguistic imperialism: African perspectives." ELT Journal. 50(2): 160167.

Powell, M. 2006. "Which knowledge? Whose reality? An overview of knowledge used in the development sector." Development in Practice 16(6): 518-32.

Romaine, S. 2013. "Keeping the promise of the Millennium Development Goals: Why language matters." Applied Linguistics Review. 4(1): 1-21.

Seargeant, P. and E. J. Erling. 2010. "The discourse of English as a language of international development: Policy assumptions and practical challenges." In Dreams and Realities: Developing Countries and the English Language. Ed Hywel Coleman, 255-274. London: British Council.

Seargeant, P., E. J. Erling, M. Solly, Q. H. Chowdhury and S. Rahman. 2017. "Analysing perceptions of English in rural Bangladesh." World Englishes, 36(4): 631-644. 
Sheldrick, G. 2017. "Foreign Aid: Let's STOP it NOW and spend BILLIONS on NHS and elderly - sign our petition." Daily Express, October 30.

https://www.express.co.uk/news/politics/870236/uk-foreign-aid-budget-british-givemoney-india-africa-taxpayer-nhs-elderly

Taylor-Leech, K. and C. Benson. 2017. "Language planning and development aid: the (in)visibility of language in development aid discourse." Current Issues in Language Planning, 18(4): 339-355.

Tesseur, W. 2017. "The translation challenges of INGOs." Translation Spaces, 6(2): 209229.

Valters, C. and B. Whitty. 2017. The Politics of the Results Agenda in DFID: 1997-2017. London: Overseas Development Institute.

Wallace, T., L. Bornstein and J. Chapman. 2007. The aid chain: Coercion and commitment in development NGOs. Oxford: Practical Action Publishing. 